\title{
Moonlight Shadow
}

\author{
Matteo Cantiello ${ }^{1}$ \\ ${ }^{1}$ Simons Foundation
}

November 30, 2021

"Like every great river and every great sea, the moon belongs to none and belongs to all. It still holds the key to madness, still controls the tides that lap on shores everywhere, still guards the lovers who kiss in every land under no banner but the sky".

E.B. White The New Yorker, July 26, 1969

\section{Where does the Moon come from?}

Scientist believe that our Moon formed out of a 'giant impact' that occurred between a Mars-sized planet and the early Earth, some 4.5 billion years ago. The Moon was then formed from the coalescence of the orbiting debris scattered during the impact.

Recent results seem to confirm this scenario

\section{What is a supermoon?}

The moon is on an elliptical orbit and its distance from the Earth varies between approximately 222,000 and $252,000 \mathrm{mi}$. A supermoon is a full moon that occurs at perigee, that is the closest approach of the satellite to Earth. A supermoon is visually larger, up to $14 \%$ in diameter, and shines $30 \%$ brighter than the moon at apogee, the farthest point on the elliptical orbit. Astronomers do not use the term supermoon, they use the much more charming term perigee-syzygy, where syzygy is a term indicating the alignment between Earth, Moon and the Sun.

\section{Does the Moon affect humans?}

There are two ways in which our moon affects life at the surface of our planet. Through Its light and its gravitational pull. The moon shines bright in the night sky, reflecting the Sun's light like an opaque mirror, leaving us contemplating its beauty at night. Not all of us, though: It is a little known fact that astronomers actually don't love the moon, having to plan their telescope observation runs when the sky prima donna is not outshining the rest of the firmament. The other important way in which the Moon leaves its mark on Earth, is through its gravitational force. Together with the Sun, the Moon induces the amazing rise and fall of sea levels, also known as tides. Tides can be quite substantial, their effect temporarily changing the landscape of many locations on Earth. The most striking example is Mt. St. Michel, a dreamy village in the north on France that, depending on the tides, shifts from being an island in the Atlantic ocean to being a hill one can reach walking on the sand. Around Mt.St.Michel, the ocean's height can change as much as $46 \mathrm{ft}$ between high and low tide. All because of the Moon.

In face of these astounding facts, one might suspect that the Moon can have a substantial effect on people as well. The belief that humans (and animals) are strongly affected by our pale satellite is widespread, and 


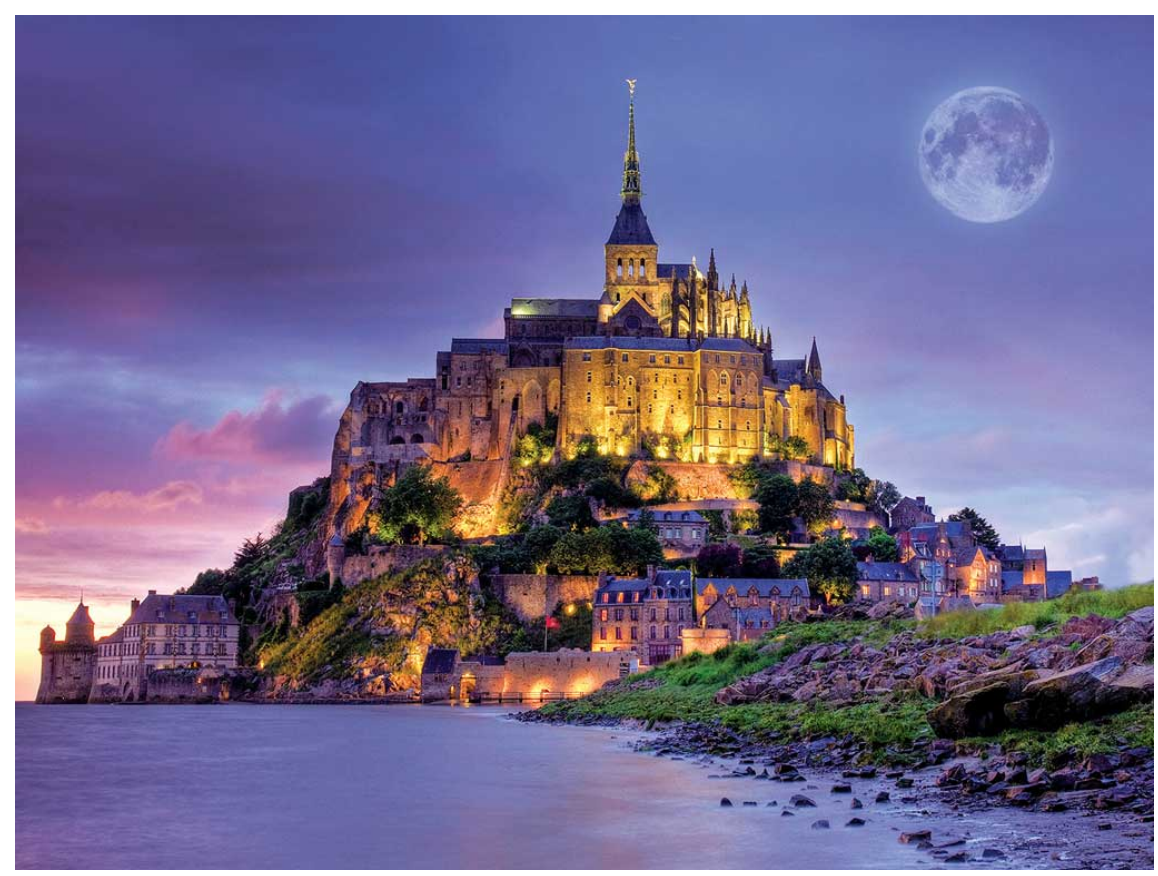

Figure 1: Mont St. Michel. Credits

it emerges in folklore, urban legends and myths from around the world. The term "lunatic", for example, derives from the Latin for "moonstruck" (in italian and spanish "Luna" means "Moon"), as people used to think that epilepsy and madness were disease caused by the moon itself. Werewolves are another mooninspired legend. Reality is that the physical effect due to the Moon' gravitational attraction is important for large bodies (like oceans) but it's negligible for humans or animals. An ocean facing closer to the moon, is being pulled more than the ocean on the far side of the planet. But for humans, this effect of tides are negligible: There is no measurable difference in the moon's gravitational effect to one side of your body vs. the other. Put it differently, when you walk your dog under a full moon, your dog's gravitational pull result in tidal forces on your body that are actually stronger than the Moon's. This is because, despite the fact your dog is not nearly as massive as the moon, the strength of tidal forces decreases as the inverse cube of the distance between objects. And the moon is quite far, more than 200,000 miles away. Yes, your Great Dane pulls much stronger! Back to the ideas that the moon has an effect on living things at the Earth's surface, studies comparing the lunar phases to births, heart attacks, deaths, suicides, violence, psychiatric hospital admissions and epileptic seizures, among other things, have over and over again found little or no connection. This said, researchers found that on days surrounding full moons, dogs have a $28 \%$ higher chance of visiting the emergency room. The exact cause was not determined, although a possibility is that taking fido out during a full moon is definitely charming, but also increases the chance of getting him hurt. You know, carried away by a moonlight shadow...

\section{A real mystery}

So no mystery at all around the Moon? Well, if you ask me, there is one thing that I find extremely puzzling. It's probably a coincidence, but it's definitely an interesting one, and it has to do with one of the most spectacular astronomical events visible to naked eye. The Sun and the Moon appear the same size in Earth's sky. In fact, while the Sun's diameter is about 400 times larger than the Moon, the Sun is also 


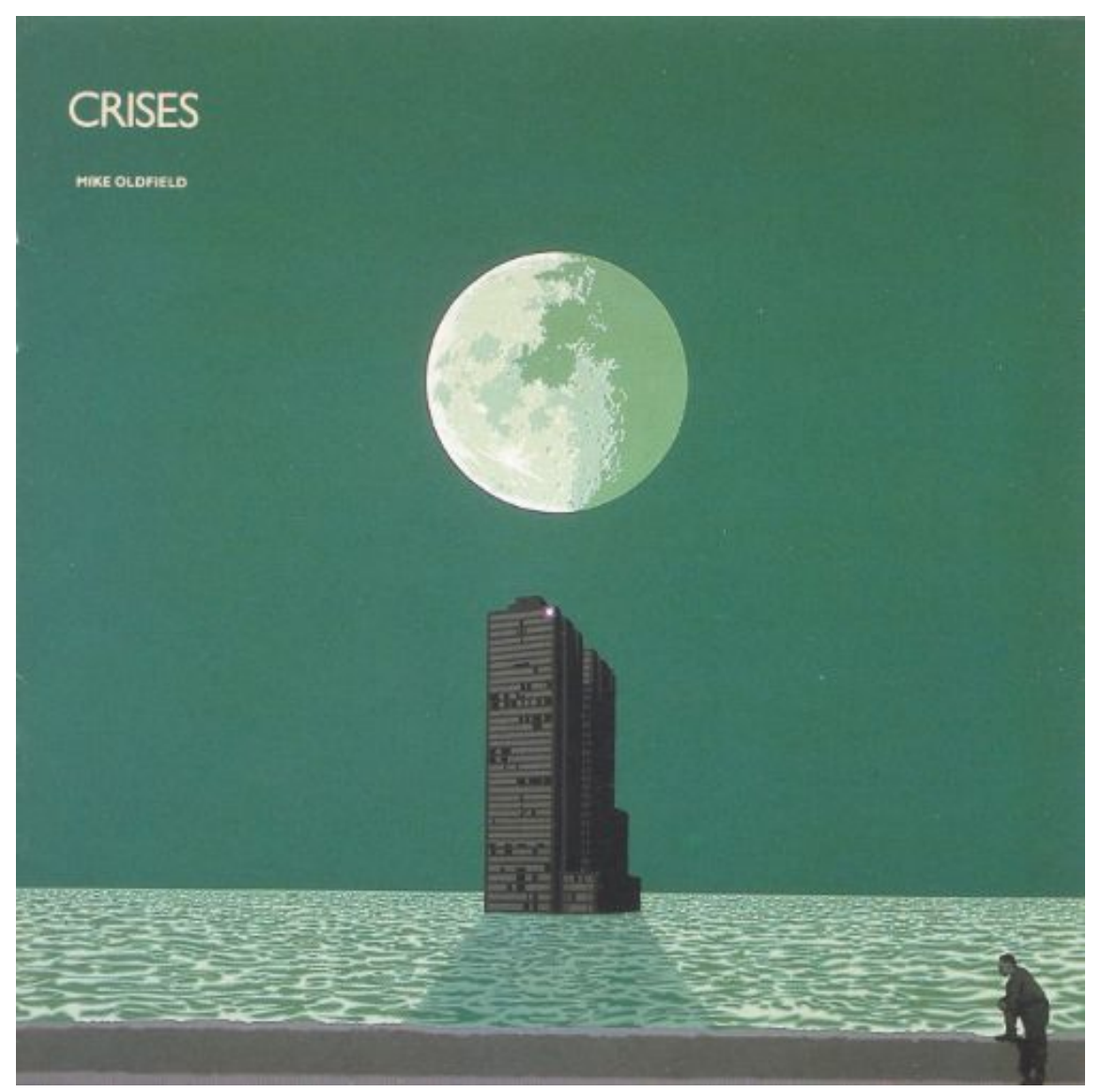

Figure 2: "Carried away by a moonlight shadow" Crises, Mike Oldfield (1983)

about 400 times farther away. There is no special reason why this should be so, and this coincidence would mostly go unnoticed if it wasn't for the fact that sometimes the Moon ends up aligned between the Earth and the Sun. When this happens, the result is a total Solar eclipse with its beautiful coronal displays, which is only possible because of the very similar projected size of the two astronomical bodies. What are the odds? Nobody really knows, but it definitely seems surprising.

What we know for sure is that the same tidal interactions that move the oceans on Earth, are causing the Moon to spiral away from our planet at a pace of about 1 inch per year. So that about 50 million years from now the Moon will appear too small to cover the Sun, and no total solar eclipses will be possible anymore. You better go and watch one asap: Next total solar eclipse in the USA? August 21, 2017! And if you miss that, there will be another one in 2024 . 


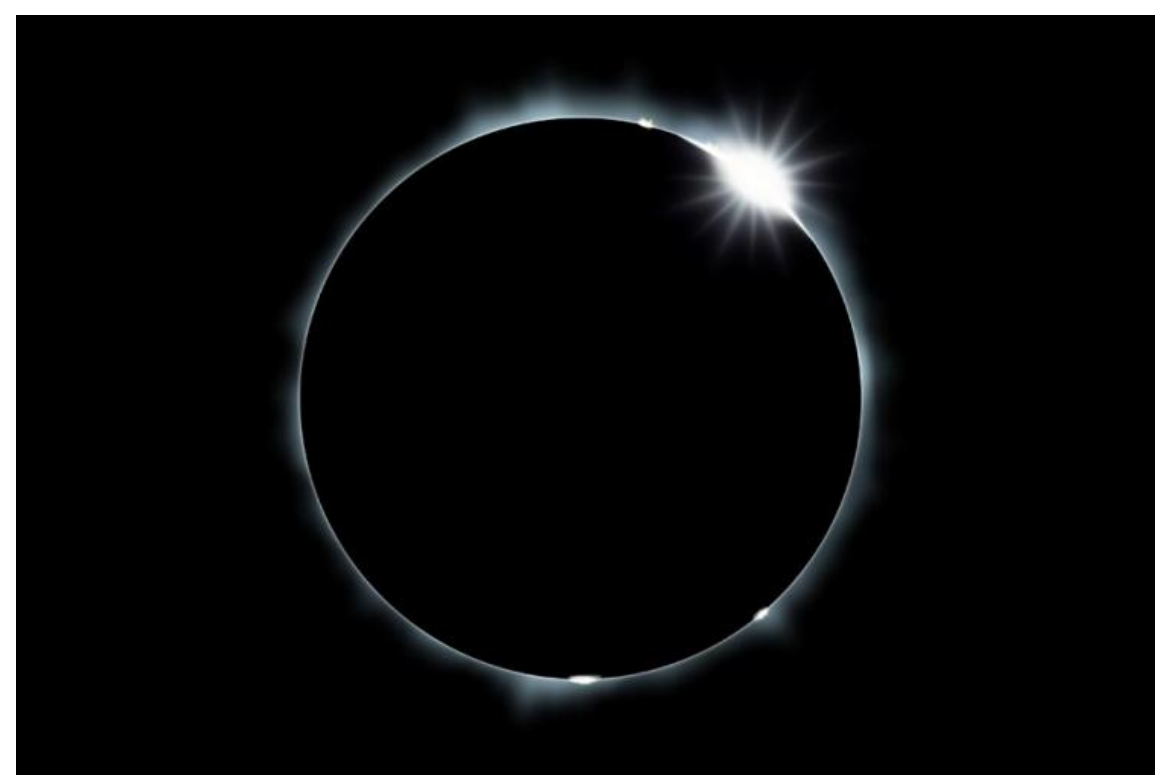

Figure 3: "And everything under the sun is in tune But the sun is eclipsed by the moon" - Eclipse, Pink Floyd 